\title{
The effectiveness of ultrasonogram guided intervention in chronic shoulder pain cases attending pain clinic of a government hospital of East zone, India: a prospective observational study
}

\author{
Pabitra Biswas ${ }^{1}$, Uttam K. Roy ${ }^{2 *}$, Purnendu Mandal ${ }^{2}$
}

${ }^{1}$ Department of Anesthesiology, ${ }^{2}$ Department of Pharmacology, Raiganj Govt. Medical College and Hospital, Raiganj, West Bengal, India

\author{
Received: 05 February 2020 \\ Revised: 14 March 2020 \\ Accepted: 18 March 2020 \\ *Correspondence: \\ Dr. Uttam K. Roy, \\ Email: Uroy951@gmail.com
}

Copyright: () the author(s), publisher and licensee Medip Academy. This is an open-access article distributed under the terms of the Creative Commons Attribution Non-Commercial License, which permits unrestricted non-commercial use, distribution, and reproduction in any medium, provided the original work is properly cited.

\begin{abstract}
Background: Ultrasonogram guided intervention in chronic shoulder pain is well known for relief of pain and improvement of range of movement (ROM) of affected shoulder joint. Ultrasonogram gives accuracy helps in localized corticosteroid delivery. Corticosteroids relieve the pain by its anti-inflammatory effect. There is conflicting evidence available regarding the effectiveness of the intervention in chronic shoulder pain, questioned in many studies. We planned this study to evaluate the efficacy of ultrasonogram guided intervention in chronic shoulder pain in a tertiary teaching hospital of rural Bengal.

Methods: The prospective observational study was carried out in 100 patients with chronic shoulder pain attending pain clinic who fulfilled predetermined inclusion criteria. Patients were injected with $40 \mathrm{mg}$ of depomethyl prednisolone and $10 \mathrm{ml}$ of $1 \%$ preservative free lignocaine via standard posterior approach. Then half an hour of standard shoulder range of motion (ROM) exercise regimen was performed under supervision. Pre injection and post injection pain level were scored by visual analogue score (VAS) shoulder exercises were taught and home-based physiotherapy was carried out by patients themselves. Patient were followed at 4, 8, and 12 weeks.

Results: The mean age of patients was $53.23 \pm 5.680$ years with $63 \%$ male study subjects, After the intervention, excellent result in VAS score and improvement of ROM observed in patients. There was statistically significant difference from baseline in both pain relief and shoulder movement.

Conclusions: USG guided intervention is effective in pain relief and in improvement in ROM in chronic shoulder pain in long term.
\end{abstract}

Keywords: Corticosteroid, Frozen shoulder, ROM, Ultrasound, VAS

\section{INTRODUCTION}

Shoulder pain is considered as the third leading cause for patients seeking musculoskeletal care. ${ }^{1}$ The musculoskeletal disorders also occupy the fourth position in years of life lost adjusted by disability. ${ }^{2}$ Many studies on musculoskeletal disorders revealed shoulder pain to be the third major complaint of the population worldwide. ${ }^{3}$ The complaints around the subacromial space structures represent $44 \%$ to $80 \%$ in patients attending pain clinic. ${ }^{4}$
In tertiary care hospitals in our developing country, most patients attending the pain clinic are from lower socioeconomic conditions. There are diverse causes of chronic shoulder pain, due to with complex anatomy of the joint. It derives either from the joint or from periarticular regions, the latter being the most frequent case..$^{5}$ This leads to difficulty in carrying out day to day work like carrying goods on the shoulder, placing things up on a shelf, painting of rooms and buildings, hammering nails, electrical fittings, farming and harvesting. Shoulder pain 
leads to disability which causes financial loss to the daily wagers. ${ }^{6}$ Hence treating these patients can not only help the individuals but also be a boost to their families and the society. When medical treatments or physical therapy procedures have failed, intervention comes into consideration. Despite the increasing understanding of the pathologies, there is still confusion about which is the most effective treatment. ${ }^{7}$ Physiotherapy can help in early stages but in established shoulder pain of synovial origin it has been proved to be of little benefit. ${ }^{8}$ Intra-articular steroid injections can lead to satisfactory results in the treatment of Frozen shoulder, with improved range of motion and early pain reduction. ${ }^{9}$ Intra articular corticosteroids, are extremely common procedures performed by physicians of primary care disciplines as well as specialists. ${ }^{10}$ While few would dispute that these procedures are easy to do and very accurate, whether image guidance can improve the outcome of intra articular procedures, were not specifically known. ${ }^{11}$ The intra-articular injection of lignocaine immediately before a physiotherapy session may relieve pain during the stretching and mobilization of the affected joint in patients with a frozen shoulder, thus enhancing the treatment effect. Immediate pain relief is a major determinant of starting physiotherapy in chronic shoulder pain. ${ }^{12}$ The early physical therapy, has considerable better outcome. In majority of cases the pain and disability associated with it demoralizes the patient, Lignocaine causes immediate pain relief, helps in increase in the range of motion (ROM) within few minutes of administration. Half an hour of ROM exercises following steroid and lignocaine administration, gives psychological boost to the patient because of immediate pain relief which increases the compliance of patients and pursuance of the physical therapy regularly. A practical approach of intra-articular injection of lignocaine and steroid followed by stretching exercises and joint mobilization is a better method because it is quick and simple procedure. Various studies had pointed out the effectiveness of intraarticular injection with different steroids but none of them had clearly pointed out the effectiveness of lignocaine that is frequently used during intra-articular injection. ${ }^{13}$ Studies of intra articular injection suggests that these may be one area where the use of image guidance is useful. The present study planned due to lack of studies evaluate the effectiveness of ultrasonography guided injection technique and outcome in working age group as ultrasonography (USG) is available in peripheral hospitals and USG guided intervention may lead to better outcome in treatment of chronic shoulder pain. There is also contradiction regarding the efficacy of local corticosteroid injection in chronic shoulder pain. ${ }^{21,22}$

\section{METHODS}

The study is prospective, observational study has been conducted at pain clinic OPD and brachytherapy OT under department of anesthesiology in a tertiary care hospital from August 2015 to July 2017. All patients in the age group of 30-80 years attending the pain clinic with shoulder pain lasting more than 3 months and fulfilling inclusion criteria are selected after taking informed consent. ASA 1, 2, 3 patients, patients with controlled hypertension and diabetes, patients not taking any steroids. Patients allergic to depomethyl prednisolone and lignocaine, pregnant patients, patients with uncontrolled hypertension and diabetes were excluded from this study.

The outcome measures were pain relief by visual analogue score (VAS) score and improvement range of movements of shoulder, namely abduction, external rotation and adduction before and after intervention by goniometer checked after 30 mins of procedure at 4 weeks, 8 weeks and 12 weeks after intervention. ${ }^{20}$ The ranges of glenohumeral joint movement were considered normal as 90 degree abduction, 90 degree external rotation and 90 degree internal rotation. Patients rated their pain on VAS of 0 to 10 with 0 representing no pain and 10 the worst pain they had ever experienced. Preinjection shoulder flexion, abduction, internal and external rotation were recorded. A uniform protocol of treatment was adopted.

The consecutive sampling method has been used; 100 patients observed in the study period for the intervention. After relevant investigations and necessary informed written consent of the procedure, the patients were asked to come in pain OT. Before the interventional procedures, baseline VAS score and the range of movements were measured. Patients were taken to the OT, pulse oximeter and NIBP will be attached, securing an I.V line. After Ultrasound exploration of the shoulder joint and adjoining areas like acromioclavicular joint, bicipital groove and rotator cuff muscles (Figure 1). Intervention was done accordingly under observation of senior anesthesiologist. Before injection of steroid all patients were tested for lignocaine sensitivity by intradermal lignocaine injection. Then the patients were injected via standard posterior approach and half an hour of standard shoulder ROM exercise regimen was performed under supervision. With the help of $40 \mathrm{mg}$. of depomethyl prednisolone and $10 \mathrm{ml}$. of $1 \%$ preservative free lignocaine After the procedure, VAS and range of movements of shoulder will be measured again after 30 mins of intervention. The same will be measured again at 4,8 and 12 weeks after procedure. Immediate pain relief and increase in ROM was observed and scored by VAS and Subjective satisfaction score. Low scores denote significant pain and poor function.

\section{Statistical analysis}

Data were analyzed using SPSS version 17 and Microsoft excel 2007. Due to small sample size the data considered as nonparametric. The data obtained were expressed as mean, SD, SEM. Statistically significant differences between groups were calculated by the application of analysis of variance (one-way ANOVA) following by 
multiple comparison tests. $\mathrm{P}$ values less than 0.05 $(p<0.05)$ were used as the significance level. As the groups were matched or paired, $>2$ observations so we applied Friedman's ANOVA with Dunn's multiple comparison test to find out statistically significant difference $(\mathrm{p}<0.05)$.

\section{RESULTS}

100 patients with chronic shoulder pain between age group 30-80 years and body weight 40-60 kg selected from patients attending pain clinic from August 2015 to July 2017. The demographic profile of patients is expressed in Table 1. Participants reported an average duration onset of symptoms $4.5 \pm 1.6$ months with a range of 3-12 months. Procedures done depicted in Table 2.

\section{Pain score}

The pain score revealed the mean baseline VAS score was $8.18 \pm 0.67$ with decrease in 4 weeks, 8 weeks and 12 weeks follow ups respectively $3.68 \pm 0.77,3.27 \pm 1.188$, $3.35 \pm 1.46,3.45 \pm 1.678$. The results show there is significant difference present between groups. (VAS B, VAS 0 AND VAS1) ( $\mathrm{p}$ value $<0.0001$ ). But there is also difference between VAS 0, VAS 1, VAS 3 which was statistically significant. But there is no significant difference between VAS 1, VAS 2, VAS 3.

\section{Range of movements}

The change of range of movement of shoulder joint over time depicted in Table 3. There is significant difference in degree internal rotation of affected shoulder at baseline, after 30 min of intervention and after 4 weeks of intervention. There is also improvement in internal rotation at 4 and 8 weeks from 30 min after intervention which was statistically significant but clinically not so much significant ( $\mathrm{p}$ value $0.0001,0.0063$ ) that can be reflected in mean \pm SEM values. There is no statistically significant difference in internal rotation at 4 weeks, 8 week and 12 weeks of intervention in comparison to $30 \mathrm{~min}$ after intervention. The external rotation also improved at $30 \mathrm{~min}$ after procedure, 4 weeks, 8 weeks, 12 weeks of intervention from baseline which was statistically significant ( $p$ value $<0.0001$ ). There is no statistically significant difference in external rotation at 4 weeks, 8 weeks, and 12 weeks of intervention in comparison to $30 \mathrm{~min}$ after intervention. There is also improvement in abduction at $30 \mathrm{~min}, 4$ weeks, 8 weeks of intervention from baseline ( $\mathrm{p}$ value $<0.0001$ ).

There is no statistical difference at 4 weeks, 8 weeks, and 12 weeks in comparison to degree of abduction of affected shoulder just 30 min after the intervention.

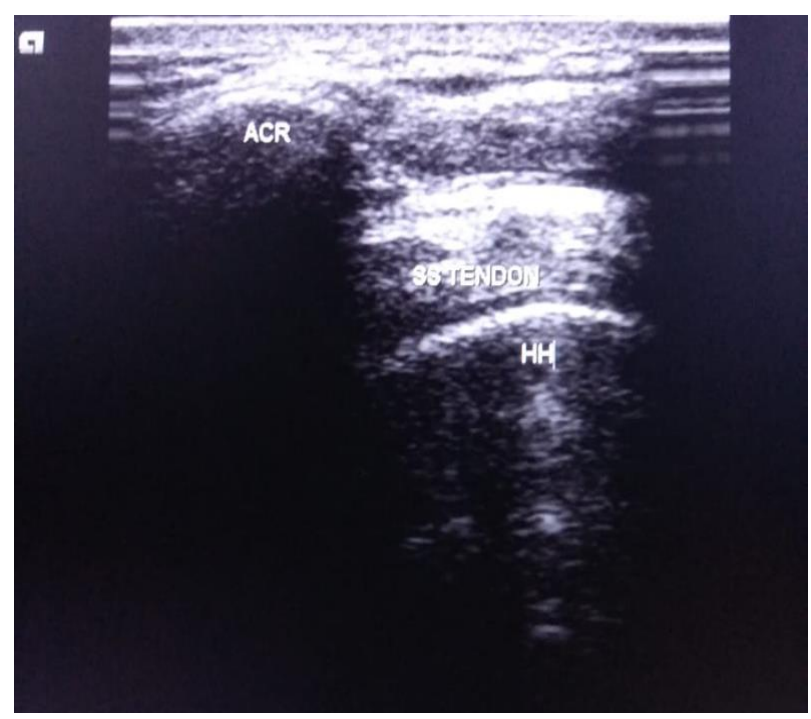

Figure 1: USG visualization of shoulder joint for intervention.

Table 1: Demographic profile of study population.

\begin{tabular}{|lll|}
\hline Variable & Mean \pm SEM & Range \\
\hline Age (in years) & $53.23 \pm 5.680$ & $30-80$ \\
\hline Body weight & $52.23 \pm 5.680$ & $40-60$ \\
\hline Gender in \% & \\
\hline Male & 63 \\
\hline Female & 37 \\
\hline
\end{tabular}

Table 2: Procedures done.

\begin{tabular}{|l|l|}
\hline $\begin{array}{l}\text { Type of procedure } \\
\text { Supra-scapular nerve } \\
\text { blocks }\end{array}$ & Total number of patients \\
\hline $\begin{array}{l}\text { Acromio-clavicular } \\
\text { joint injection }\end{array}$ & 25 \\
\hline $\begin{array}{l}\text { Bicipital groove } \\
\text { injection }\end{array}$ & 15 \\
\hline
\end{tabular}

Table 3: Change of range of movement of shoulder joint over time.

\begin{tabular}{|lllllll|}
\hline Movements & Baseline & $\begin{array}{l}\mathbf{3 0} \text { min after } \\
\text { intervention }\end{array}$ & $\begin{array}{l}\text { 4 weeks after } \\
\text { intervention }\end{array}$ & $\begin{array}{l}\mathbf{8} \text { weeks after } \\
\text { intervention }\end{array}$ & $\begin{array}{l}\text { 12 weeks after } \\
\text { intervention }\end{array}$ & $\begin{array}{l}\text { P value } \\
\text { between } \\
\text { group }\end{array}$ \\
\hline Internal rotation & $49 \pm 5.8$ & $72 \pm 5.1$ & $72 \pm 6.6$ & $72 \pm 8.2$ & $72 \pm 8.5$ & $<0.0001$ \\
\hline Abduction & $90 \pm 3.6$ & $135 \pm 10$ & $135 \pm 12$ & $135 \pm 13$ & $134 \pm 14$ & $<0.0001$ \\
\hline External rotation & $43 \pm 2.6$ & $66 \pm 6.1$ & $66 \pm 7.5$ & $65 \pm 7.9$ & $65 \pm 7.9$ & $<0.0001$ \\
\hline
\end{tabular}




\section{DISCUSSION}

Mean age of patients was $53.23 \pm 5.680$ years similar to that reported in several other studies. ${ }^{13,14}$ In our study, the degree of pain relief and the range of movement were significantly improved after treatment in study population. In our study we noted more male preponderance unlike other studies. ${ }^{13,15}$ Studies showed that USG guided intervention is effective in treatment of chronic shoulder pain of various etiology. ${ }^{16,17}$

In our study we found out significant improvement in VAS score in comparison to baseline to final follow up. Most studies show similar results. ${ }^{13,14,19} \mathrm{We}$ found equal efficiency of ultrasound-guided local anesthetic injection around shoulder joint terms of pain relief, improvement in function, and passive ROM of the affected shoulder. The effect was prolonged and sustained even at the 6th week of follow-up with diabetes mellitus the most associated comorbidity. The result was not consistent with many studies, few reported short term benefit with repeat injection of corticosteroid for chronic shoulder pain and questionable benefit of range of movement in diabetic patients. ${ }^{17}$ There are conflicting evidence of efficacy of USG Guided corticosteroid injection in chronic shoulder pain in many meta-analysis and reviews. ${ }^{21,22,24}$ Some studies have demonstrated improvement in shoulder symptoms irrespective of positioning of the needle was in the targeted structure or not. ${ }^{23}$ Review suggest patients who underwent USG guided injections had statistically significant greater improvement in shoulder pain and function at 6 weeks after injection and also had less adverse events but the results should be interpreted with some caution due to the limited number of studies and small sample sizes of the two included studies. ${ }^{24}$

The limitation of our study being an observational one, we planned to compare conventional technique with USG guided injection in future. Particularly with self-reporting assessments were also our limitation. The small sample size is another limitation.

\section{CONCLUSION}

We conclude image-guided (ultrasound) corticosteroid injections potentially offer a significantly greater clinical improvement in adults with chronic shoulder pain both in terms of pain relief and improvement of range of movement.

\section{Funding: No funding sources}

Conflict of interest: None declared

Ethical approval: The study followed the principles of Declaration of Helsinki (as revised in 2013) and Indian Council of Medical Research (ICMR) ethical guidelines for clinical research

\section{REFERENCES}

1. Gonzalez FJ, Cassia LTD, Jaqueline M, Silva SCD, Siriani OAD. Musculoskeletal shoulder complaints: characteristics of patients and consultations in primary care. Fisioter Pesqui. 2019;26(1):78-84.

2. Smith E, Hoy DG, Cross M, Vos T, Naghavi M, Buchbinder R, et al. The global burden of other musculoskeletal disorders: Estimates from the Global Burden of Disease 2010 study. Ann Rheum Dis. 2014;73(8):1462-9.

3. Kinge JM, Knudsen AK, Skirbekk V, Vollset SE. Musculoskeletal disorders in Norway: Prevalence of chronicity and use of primary and specialist health care services. BMC Musculoskelet Disord. 2015;16(1):1-9.

4. Kinge JM, Knudsen AK, Skirbekk V, Vollset SE. Musculoskeletal disorders in Norway: Prevalence of chronicity and use of primary and specialist health care services. BMC Musculoskelet Disord. 2015;16(1):1-9.

5. Linaker $\mathrm{CH}$, Walker-Bone K. Shoulder disorders and occupation. Best Pract Res Clin Rheumatol. 2015;29(3):405-23.

6. Kuijpers T, Windt DA, Heijden GJ, Bouter LM. Systematic review of prognostic cohort studies on shoulder disorders. Pain. 2004;109(3):420-31.

7. Artus M, Holt TA, Rees J. The painful shoulder: an update on assessment, treatment, and referral. $\mathrm{Br} \mathrm{J}$ Gen Pract. 2014;64(626):593-5.

8. Green S, Buchbinder R, Hetrick SE. Physiotherapy interventions for shoulder pain. Cochrane Database of Systematic Reviews 2003, Issue 2. Art. No.: CD004258.

9. Lorbach O Anagnostakos K, Scherf C, Seil R, Kohn D, Pape D. Nonoperative management of adhesive capsulitis of the shoulder: oral cortisone application versus intra- articular cortisone injections. J Shoulder Elbow Surg. 2010;19:172-9.

10. Koh KH. Corticosteroid injection for adhesive capsulitis in primary care: a systematic review of randomised clinical trials. Singapore Med J. 2016;57(12):646-57.

11. Bloom JE, Rischin A, Johnston RV, Buchbinder R. Image-guided versus blind glucocorticoid injection for shoulder pain. Cochrane Database of Systematic Reviews 2012;8:CD009147.

12. Hsu WC Wang TL, Lin YJ, Hsieh LF, Tsai CM, Huang KH. Addition of Lidocaine Injection Immediately before Physiotherapy for Frozen Shoulder: A Randomized Controlled Trial. PLoS ONE. 2015;10(2):0118217.

13. Pandey A, Shrestha B, Shrestha K. A Comparative Study of Steroid Injection With or Without Lignocaine in Treating Frozen Shoulder. J Univ Coll Med Sci. 2018;5(1):22-28.

14. Mitra, Kumar P, Bhattacharya, Dipasri. Comparison of clinical effects of ultrasound guided suprascapular nerve block and oral pregabalin versus suprascapular 
nerve block alone for pain relief in frozen shoulder. Indian J Pain. 2016;30:49.

15. Verma, Kumar D, Neyaz, Osama, Nanda, Srishti, et al. Comparison of outcome of ultrasound-guided suprascapular nerve block versus intra-articular steroid injection in adhesive capsulitis of shoulder: A randomized control trial. Indian $\mathbf{J}$ Rheumatol. 2019;14:11-19.

16. Hsieh, Fen L, Hsu, Li W, Lin, Jia Y, Huiwu S, Chang, Chwen K, Chang, Lan H. Is UltrasoundGuided Injection More Effective in Chronic Subacromial Bursitis. Medicine and science in sports and exercise. 2013;45(10):1249.

17. Blonna D, Bonasia DE, Mattei L, Bellato E, Greco V, Rossi R. Efficacy and Safety of Subacromial Corticosteroid Injection in Type 2 Diabetic Patients. Pain Res Treat. 2018;2018:9279343.

18. Artus, Majid, Holt, Tim, Rees, Jonathan. The painful shoulder: An update on assessment, treatment, and referral. The British journal of general practice: the $\mathrm{J}$ Royal College General Practitioners. 2014;64:593-5.

19. Ginn, Karen, Cohen, Milton. Exercise therapy for shoulder pain aimed at restoring neuromuscular control: a randomized comparative clinical trial. J of rehabilitation medicine: official J UEMS European Board Physical Rehabilitation Med. 2005;37:115-22.
20. Norkin CC, White DJ. Measurement of Joint Motion: A Guide to Goniometry. Philadelphia: FA. Davis Co; 2003: 70-90.

21. Buchbinder R, Green S, Youd JM: Corticosteroid injections for shoulder pain. Cochrane Database Syst Rev. 2003;1:CD004016.

22. Arroll B, Smith GF: Corticosteroid injections for painful shoulder: a meta-analysis. Br J Gen Pract. 2005;55:224-8.

23. Hegedus EJ, Zavala J, Kissenberth M, Cook C, Cassas K, Hawkins R, Tobola A. Positive outcomes with intra-articular glenohumeral injections are independent of accuracy. J Shoulder Elbow Surg. 2010;19:795-801.

24. Soh E, Li W, Ong KO, Chen W, Bautista D. Imageguided versus blind corticosteroid injections in adults with shoulder pain: a systematic review. BMC Musculoskelet Disord. 2011;12:137.

Cite this article as: Biswas P, Roy UK, Mandal P. The effectiveness of ultrasonogram guided intervention in chronic shoulder pain cases attending pain clinic of a government hospital of East zone, India: a prospective observational study. Int J Basic Clin Pharmacol 2020;9:748-52. 